\title{
TODO JUNTO Y SIMULTÁNEO: UN ANÁLISIS DE LA ESTRUCTURA DE LA NOVELA EL GATO DE SÍ MISMO, DE URIEL QUESADA
}

\author{
José Pablo Rojas González
}

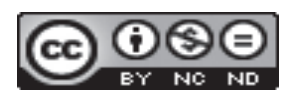

Esta obra está bajo una licencia Creative Commons

Reconocimiento-No Comercial-Sin Obra Derivada 



\title{
TODO JUNTO Y SIMULTÁNEO: UN ANÁLISIS DE LA ESTRUCTURA DE LA NOVELA EL GATO DE SÍ MISMO, DE URIEL QUESADA
}

\author{
ALL MIXED TOGETHER AT ONCE: AN ANALYSIS OF THE STRUCTURE \\ OF THE NOVEL EL GATO DE SÍ MISMO, BY URIEL QUESADA
}

\section{José Pablo Rojas González}

\begin{abstract}
RESUMEN
El presente trabajo busca estudiar -a partir de los aportes teóricos de Mijaíl Bajtín- la estructura de la novela El gato de sí mismo, de Uriel Quesada. Se pretende caracterizar este trabajo literario costarricense dentro del género novela -específicamente como novela polifónica-, a partir de la coexistencia de otros subgéneros literarios y de su carencia de unidad monológica, según lo apuntado por el teórico ruso.

Palabras clave: novela costarricense, estructura, polifonía bajtiniana, Quesada-Uriel,carnavalización.
\end{abstract}

\section{ABSTRACT}

This paper seeks to study -from the theoretical contributions of Mikhail Bakhtin- the structure of Uriel Quesada's novel, El gato de sí mismo. The article seeks to characterize this Costa Rican literary work within the genre novel -specifically as polyphonic novel-. This definition of Quesada's novel is based on the coexistence of other literary subgenres and on the lack of monologic unity, as noted by the Russian theorist.

Key words: Costa Rican novel, structure, bakhtinian polyphony, Quesada-Uriel, carnavalization.

\section{A manera de introducción: La novela polifónica}

La novela, a partir de las aportaciones de Mijaíl Bajtín, sólo puede caracterizarse como un género multifacético, siempre en proceso de formación. Esta particularidad es la que, en efecto, enriquece a este género que, finalmente, se puede definir como «sospechoso», en el sentido en que presenta en sí una gran diversidad de otros géneros, los cuales no permiten su definición o, mejor, establecen su indefinición. Por lo anterior, es importante, en este punto, trabajar algunas nociones básicas en torno a lo planteado por Bajtín sobre la novela polifónica, con el fin de tener un punto de partida para el análisis que ahora se quiere llevar a cabo con la novela de Uriel Quesada.

ML. José Pablo Rojas González. Universidad de Costa Rica. Profesor en la Escuela de Estudios Generales. Costa Rica.

Correo electrónico: josepablo.rojasgonzalez@ucr.ac.cr

Recepción: 14- 01- 2014

Aceptación: 27- 02- 2014 
Bajtín, en su trabajo Problemas de la poética de Dostoievski, desde su estado de la cuestión, expone las características que hacen singular a la novela de este autor. Explica, así, cómo esta se distingue por una "auténtica polifonía de voces autónomas" (Bajtín, 2003, p. 15). La polifonía hay que entenderla como esa característica que, en los textos literarios, conjunta diversas conciencias independientes, que resultan en un trabajo de subjetivación de los héroes mismos de este tipo de textos. Afirma Bajtín: "Los héroes principales de Dostoievski, efectivamente, son, según la misma intención artística del autor, no sólo objetos de su discurso, sino sujetos de dicho discurso con significado directo." (Bajtín, 2003, p. 15). La polifonía bajtiniana se opone, entonces, a la existencia de un «yo» individual; así, el «sujeto» no puede ser más que un «sujeto» plural, en el sentido en que está atravesado por el lenguaje: los sujetos interactúan con muchas otras voces ajenas, muchos otros discursos que han asimilado y que se activan en el momento mismo en el que se habla.

Bajtín explica que todos los elementos de la estructura novelesca en Dostoievski son singulares (en relación, claro, con las novelas de tipo monológico), singulares porque están determinados por "[...] la tarea de formar un mundo polifónico y de destruir las formas establecidas de la novela europea, en su mayoría monológica (homófona)." (Bajtín, 2003, p. 16) Este teórico afirma que, desde el punto de vista de la novela monológica (y su correspondiente comprensión del mundo representado), el mundo en los textos polifónicos puede parecer desordenado y la estructura de ellos puede parecer un conjunto de elementos diversos e incompatibles. Sin embargo, con un análisis de la finalidad artística de estos textos, pueden explicarse esas "alteraciones" para comprender la coherencia de estas características.

Precisamente, esto es lo que ahora se pretende lograr con El gato de sí mismo, de Uriel Quesada: estudiar su especial textualidad, para así poder aprehender esta novela de la manera más orgánica posible, entendiéndola no como un texto "esquizofrénico" (como lo define Albino Chacón en la contraportada de la novela), sino como uno que se regodea en sus múltiples posibilidades estéticas. Es, entonces, relevante anotar, desde ya, lo que Bajtín señala para el caso de Dostoievski (a partir de unas afirmaciones del crítico Viacheslav Ivanov): este tipo de novelas no se quedan en un puro principio de estructuración literaria concreto sino que plantean una visión artística del mundo: el género novela mismo se conforma como «una totalidad artística verbal», como se tratará de demostrar aquí a partir del texto de Quesada.

Entonces, la novela polifónica es, desde la teoría bajtiniana, aquella que conjunta los elementos más dispares para distribuirlos entre varios mundos y varias conciencias con los mismos derechos: "[...] no se dan en un mismo horizonte sino en varios, completos y equitativos, y no es el material inmediato sino estos mundos, estas conciencias con sus horizontes, los que se combinan en una unidad suprema, es decir, en la unidad de la novela polifónica" (Bajtín, 2003, p. 29). La clave artística de la novela polifónica está, entonces, en la relación entre el principio estructural -"unión de elementos heterogéneos e incompatibles"- con "la pluralidad de centros no reducidos a un común denominador ideológico" (Bajtín, 2003, p. 31). Evidentemente, contrario a la novela monogal, la novela polifónica conjunta lo disímil (con todas las contradicciones que esto implique), pero para justificar los puntos de vista más discordantes, para darles una base en el texto-novela mismo. La novela polifónica, en este sentido, es novela humana, ya que admite lo heterogéneo y lo contradictorio, rasgos que no sólo se dan en la estructura del texto, sino, también, en la misma intención artística. Afirma Bajtín: "[...] la voluntad artística de la polifonía es voluntad por combinar muchas voluntades, es voluntad del acontecimiento” (Bajtín, 2003, p. 38). 
Coexistencia e interacción son las dos principales características de la visión artística que Bajtín señala en Dostoievski y que, por ende, se pueden extender al trabajo realizado en la novela polifónica en general. Estas se explican por esa necesidad de organizar, dentro de un solo tiempo, todo el material semántico y real, como apunta Bajtín. Lo anterior es importante tenerlo en cuenta en la medida en que el material textual y discursivo de la novela polifónica se presenta como "todo junto y simultáneo", y son precisamente estas características las que permiten entender este tipo de textos como textos dinámicos, que se mueven en el espacio y en el tiempo, y que llevan a sus héroes a vivir en el aquí y en el ahora. Afirma Bajtín: “[...] sus héroes no recuerdan nada, no tienen biografía en el sentido de algo pasado y totalmente agotado. Recuerdan de su pasado sólo aquello que no deja de ser para ellos el presente y que se vive por ellos como tal [...]" (Bajtín, 2003, p. 49) Y sigue: "Cada acto del héroe se encuentra completamente en el presente y en este sentido no está predeterminado; se piensa y se representa por el autor como un acto libre" (Bajtín, 2003, p. 50).

Como explica el teórico ruso, la estructura de la novela polifónica es la que, en sí misma, permite la representación de un mundo con una coexistencia y una integración artísticamente organizadas, lo que -desde la perspectiva de la novela monológica- se entiende, más bien, como caóticas. En estos textos -afirma- hay una heterogeneidad espiritual, no hay un proceso de formación, no se presentan las etapas del desarrollo de un espíritu único.

Lo anterior sólo es posible entenderlo en relación con el concepto de "conciencia" que, según Bajtín, Dostoievski desarrolla siempre a partir del vínculo con la otredad; es decir:

La conciencia en Dostoievski nunca es autosuficiente sino que se vincula intensamente a otra. Cada vivencia, cada pensamiento del héroe son internamente dialógicos, polémicamente matizados, resistentes o, por el contrario, abiertos a la influencia ajena, y en todo caso no se concentran simplemente en su objeto sino que se orientan siempre al otro hombre. (Bajtín, 2003, p. 50)

En efecto, lo importante es la interacción y la interdependencia. Lo vital en la polifonía, bien lo destaca el teórico ruso, consiste en el hecho de que todo tiene lugar entre conciencias diversas. Esto no hay que desligarlo de la estructura de la novela polifónica misma, que Bajtín entiende como enteramente dialógica; es decir, configurada con base en «el contrapunto artístico», que este autor explica de la siguiente manera: "Son varias voces que cantan de manera diferente un mismo tema. Esta es, precisamente, la polifonía que descubre el carácter polifacético de la vida y la complejidad de las vivencias humanas" (Bajtín, 2003, p. 70).

\section{Los géneros cómico-serios}

Bajtín, a la hora de analizar la historia de los géneros (con el fin de esclarecer más aún la heterogeneidad genérica y estilística en Dostoievski), plantea que la novela tiene tres raíces principales: la epopeya, la retórica y el carnaval. A partir de ellas, indica que la novela dialógica le debe mucho a dos géneros cómico-serios, en específico: al diálogo socrático y a la sátira menipea. En este sentido, hay que señalar las características que Bajtín recoge sobre estos géneros, ya que la estructura, la composición de la novela polifónica está compenetrada por sus elementos. ${ }^{1}$

Respecto al diálogo socrático, Bajtín señala sus "momentos" más relevantes, siempre en relación con su trabajo sobre Dostoievski. Así, indica los siguientes: 
a. Naturaleza dialógica de la verdad y del pensamiento humano acerca de esta. Afirma Bajtín: "La verdad no nace ni se encuentra en la cabeza de un solo hombre, sino que se origina entre los hombres que la buscan conjuntamente, en el proceso de su comunicación dialógica" (Bajtín, 2003, p. 161). Evidentemente, la importancia de este punto está en su oposición a cualquier monologismo oficial y a su pretensión por poseer una verdad ya hecha.

b. Procedimientos del diálogo socrático: síncrisis y anácrisis. La síncrisis era una confrontación de diversos puntos de vista sobre un objeto determinado. La anácrisis se refiere a los modos de provocar el discurso del interlocutor.

c. Protagonista-ideólogo. El diálogo socrático introduce la figura de su participante como un ideólogo, ya que el mismo acontecer de este tipo de diálogo es, en sí, un acontecimiento claramente ideológico de la indagación de la verdad y de su puesta a prueba.

d. En el diálogo socrático se recurre, a veces con el mismo fin, a la situación temática del diálogo. Explica Bajtín: “[...] hay una tendencia hacia la creación de una situación excepcional que purifica la palabra de todo automatismo y el carácter cosificado de la vida y obliga al hombre a descubrir los estratos profundos de la personalidad y del pensamiento" (Bajtín, 2003, p. 163).

e. Actitud libre y creadora hacia la imagen de la idea. Afirma Bajtín: "Las ideas de Sócrates, de los sofistas principales y de otros personajes históricos no se citan ni se reproducen aquí, sino que se dan dentro de un desarrollo libre y creador junto con otras ideas que las dialogizan” (Bajtín, 2003, p. 164).

Sobre la sátira menipea, Bajtín señala las siguientes características principales de este género carnavalizado: ${ }^{2}$

a. Presencia del elemento de la risa (a veces en mayor grado que en el diálogo socrático).

b. Está libre de la tradición literaria, y no se limita por ninguna exigencia de verosimilitud externa: "[...] se destaca por una excepcional libertad de la invención temática filosófica. [...] Quizás en toda la literatura universal no hallemos un género tan libre en cuanto a la invención y la fantasía como ella" (Bajtín, 2003, p. 167).

c. Crea situaciones excepcionales para poner a prueba la idea filosófica, la palabra y la verdad. Afirma este teórico: "Con frecuencia, la fantasía adquiere un carácter de aventura, a veces simbólica o incluso místico-religiosa, pero siempre la aventura se somete a la función netamente ideológica de provocar y poner a prueba la verdad" (Bajtín, 2003, p. 167).

d. Combinación orgánica de la libre fantasía, del simbolismo (y a veces de elementos místicos-religiosos) con un naturalismo de bajos fondos, como lo define Bajtín.

e. Conjunción de la fantasía y la invención con un universalismo filosófico excepcional y con la extrema capacidad de contemplación del mundo. A la menipea la caracteriza la confrontación de las «últimas cuestiones» del mundo.

f. Aparece una estructura en tres planos: la acción y las síncrisis dialógicas se trasladan de la tierra al Olimpo o a los infiernos.

g. Aparece un tipo específico de fantasía experimental (véase, al respecto, el Icaromenipo de Luciano o el Endimión de Varrón, como apunta Bajtín). 
h. Aparece lo que podría llamarse la experimentación psicológico-moral: "[...] la representación de estados inhabituales, anormales, psíquico-morales del hombre, toda clase de demencias ("temática manical"), desdoblamiento de la personalidad, ilusiones irrefrenables, sueños raros, pasiones que rayan en la locura, suicidios, etc." (Bajtín, 2003, p. 170) Y sigue: "Sueños, visiones y locura destruyen la integridad épica y trágica del hombre y su destino: manifiestan las posibilidades de otro hombre y de otro destino en la persona que pierde su carácter concluso y simple y deja de coincidir consigo misma" (Bajtín, 2003, p. 171).

i. Se presentan escenas de escándalos, de conductas excéntricas, de discursos y apariciones inoportunas: "Los escándalos y las excentricidades destruyen la integridad épica y trágica del mundo, abren una brecha en el curso irrevocable y normal ("venerable") de asuntos y sucesos humanos y liberan la conducta humana de las normas y motivaciones que la predeterminan” (Bajtín, 2003, p. 172).

j. Este género está lleno de oxímoros y de marcados contrastes.

k. Incluye, de manera usual, elementos de utopía social. Normalmente en forma de sueños o viajes a países desconocidos.

1. Se caracteriza por un amplio uso de géneros intercalados, en prosa y en verso: cuentos, cartas, discursos oratorios, simposios, etc. Se dan con diferentes grados de parodia y de objetivación.

m. Hay una pluralidad de estilos y tonos de este género, sobre todo por la presencia de los géneros intercalados.

n. La última característica es su carácter de actualidad más cercana.

Todas estas características se han regenerado y renovado con la novela polifónica, desde la figura de Dostoievski. La menipea, sin embargo, no participaba de la polifonía de los textos del autor ruso, aunque esta preparó las condiciones para que ella se diera. Es, finalmente, la carnavalización literaria (como se apuntó antes) la que promoverá aún más la riqueza de voces en estos géneros, su polifonía.

\section{El gato de sí mismo: Una estructura juguetona}

La polifonía, como se trató de explicar anteriormente, hay que entenderla a partir de la conjunción de diversas conciencias independientes, que resultan en un trabajo de subjetivación de los héroes mismos de este tipo de textos. En este sentido, la polifonía bajtiniana se opone a la existencia de un «yo individual»: el «sujeto» no puede ser más que un «sujeto plural». Esta pluralidad se encontrará, en El gato de sí mismo, en el narrador, quien es a la vez el protagonista de todo el texto (texto que, desde su voz, es definido como una autobiografía). Este narrador, como se evidenciará, es quien activa toda la heterogeneidad genérica y estilística en esta novela del autor costarricense Uriel Quesada.

El gato de sí mismo está dividido en tres partes: la primera, la segunda y un "epílogo y rebobinado". La primera inicia con la narración de la llegada del narrador-protagonista a su ciudad natal. En esta parte, precisamente, se evidencia esa capacidad "imaginativa" por parte de Germán Đ El Gado. La imaginación, en esta novela, hay que entenderla como "[...] la facilidad para formar nuevas ideas, nuevos proyectos, etc.” (DRAE, versión en línea), a partir del lenguaje mismo. La riqueza discursiva de este texto hay que verla siempre en relación con 
esta capacidad del narrador de reunir los elementos más dispares en su propio discurso, de decirse y de contar en un movimiento constante de lenguaje, de discursos, de ideas.

Bajtín ha señalado, para los géneros del dominio de lo cómico-serio, tres rasgos principales. El primero es una nueva actitud hacia la realidad: el "[...] punto de partida de estos géneros para la comprensión, valoración y tratamiento de la realidad es la actualidad más viva y a menudo directamente cotidiana" (Bajtín, 2003, p. 158). El segundo se refiere a la fundamentación consciente de los géneros cómico-serios en la experiencia y en la libre invención. Y, finalmente, como tercer rasgo, está esa explícita heterogeneidad de estilos y de voces presente en este tipo de textos:

\footnotetext{
Los caracteriza la pluralidad de tono en la narración, la mezcla de lo alto y lo bajo, de lo serio y lo ridículo, y utilizan ampliamente los géneros intercalados (cartas, manuscritos encontrados, diálogos narrados, parodias de los géneros altos, citas con acentuación paródica, etc.); en algunos de estos géneros se observa una mezcla de prosa y verso, se introducen los dialectos y las jergas vivas [...], aparecen diversas máscaras para el autor. Junto con la palabra que representa, aparece la palabra representada: en algunos géneros, el papel principal pertenece al discurso bivocal. (Bajtín, 2003, p. 159)
}

Así las cosas, es claro que esta novela se sirve de la re-creación, y se presenta como un "collage". ${ }^{3}$ La intertextualidad que se le puede señalar hay que entenderla como el resultado del agregado de varios elementos que interactúan inevitablemente. Así, se tiene un discurso en el que se cruzan muchos otros discursos, y en esta acción recíproca se renominan, se resignifican, pues, como afirma Reyes, siguiendo a Bajtín, "[...] la palabra en el lenguaje es parcialmente ajena. Se convierte en propia cuando el hablante la empapa con su propia intención, su propio acento: cuando se la apropia para adaptarla a lo que quiere expresar" (Citado en Calsamiglia y Tusón, 1999, p. 149).

Entonces, el intertexto hay que definirlo, para el caso de esta novela costarricense, como un "factor de producción o transformación del sentido", como afirma María Amoretti, en su Diccionario de términos asociados en teoría literaria (Amoretti, 1992, p. 69). Este factor, además, es fundamental para explicar el movimiento de huida y ocultamiento que, como se verá, caracteriza a Germán Germanóvich. Así, la intertextualidad no es más que otro término para definir un trabajo de "travestización literaria" que se da tanto en la narración de Germán como en su configuración identitaria.

Al respecto de la heterogeneidad (paródica) presente en la novela de Quesada, es necesario introducir algunos extractos que ejemplifiquen los diferentes géneros con los que «juega» Germán. Pero, de nuevo, es necesario señalar el papel fundamental de lo carnavalesco como ese principio unificador que relaciona los más variados elementos en la novela del autor costarricense: el principio carnavalesco es la columna vertebral de El gato de sí mismo, como se podrá colegir a lo largo de este trabajo. Véanse, pues, las siguientes citas:

Guión de película:

La historia ocurría en París durante la ocupación alemana. Estábamos en una boîte apretada de gente y olor a tabaco. Yo bailaba can-can con las folles bergères, Rasputina era un oficial nazi que me miraba desde una mesa en primera fila. (Quesada, 2005, p. 52)

\section{Romance:}

Hoy Germán no se menciona

Su nombre está prohibido

Hace penar al monarca

$\mathrm{Y}$ al infractor ir a presidio. (Quesada, 2005, p. 85) 


\title{
Relato del Lejano Oeste:
}

El sheriff formó un pequeño contingente de responsables del orden, quienes tenían a cargo vigilar los puntos más conflictivos de T or C [el pueblo de Truth or Consequences], así como montar guardia durante las paradas de las diligencias. (Quesada, 2005, p. 205)

\section{Poema:}

\section{Poema griego}

No esperes recompensa en Versalles, sin su horrible existencia nunca hubieras buscado camino.

Cuando encuentres Versalles

tal y como lo dejaste comprenderás por fin el significado de los falsos viajes. (Quesada, 2005, p. 336)

\section{Canción:}

Luego de la introducción con saxo tenor, trombón y respuesta de piano, Dios toma el micrófono y canta: Ayer todo era pena, mi negra,

hoy te canto mi alegría.

Al final del túnel hay salida, compré mucha lotería.

\author{
Tú quería un visón, \\ Comprá en Parí y Niu Yo. \\ Pa' llá tomaremo avión \\ Apena pegue el mayor. (Quesada, 2005, p. 182)
}

\section{Proclama:}

Pueblo de la muy noble y leal ciudad de Cartago, declarada ansí por Su Majestad don Felipe II en el mil quinientos y cincuenta y tres de la era de Nuestro Señor Jesucristo, prestad atención. Durante las últimas horas, funestos rumores han tratado de crear duda y pánico entre todos vosotros. Se dice que nuestro Rey, don Luis Dieciséis, perdió la vida en aventura galante y escandalosa. (Quesada, 2005, p. 144)

\section{Ronda:}

Ronda lironda ronda

¿A dónde va en tan gracioso corcel

El caballero don Hernán?

¿A matar al ogro comeniños?

¿A vencer al moro de ojos rubios y pelo azul?

Ronda lironda ronda

¿A dónde va tan apuesto y galán?

iA despertar princesas de

Labios de mazapán! (Quesada, 2005, p. 110)

\section{Discurso-diatriba:}

Recordad: hace siglos la decencia nos ejecutó, nuestra sangre corrió por la calles de Cartago hasta que nos secamos, nos convertimos en fantasmas de feria que no asustan sino que mueven a la compasión [...]. Yo defiendo esos principios, soy un viudo noble, tengo un apellido y lo protejo, por eso te entrego en sacrificio. ¿Tenéis voluntad para ello? Os pregunto aunque no me importa lo que digáis. (Quesada, 2005, p. 62)

La teoría bajtiniana en torno a la novela polifónica es clara sobre el valor que, para la novela moderna, representan estos rasgos, rasgos que se están tratando de evidenciar en El gato de sí mismo. En esta novela, en efecto, la comprensión, valoración y tratamiento 
de la realidad más cotidiana se da desde lo artístico. Esa imaginación no es sino un acto consciente por reinventar la experiencia (a través del lenguaje, claro está). Germán Đ El Gado, conscientemente, mezcla - con su narración- muchos discursos. Su actitud hacia la palabra es, por ello, novedosa, sobre todo en la medida en que, para él, es siempre material literario. Al respecto, véase el siguiente ejemplo, en el que se narra el momento en el que el personaje se baja de un autobús:

\footnotetext{
Quienes no pueden lanzarse a tiempo se agolpan en el pasillo, tropiezan con mi maletita de cartón, tratan de pasar por encima de mí. Yo resisto hasta el último momento. El chofer acciona el freno manual en tanto tomo la decisión de levantarme y utilizar la salida delantera. Me digo: "Ladies and gentleman, la Cenicienta está a punto de descender con sus zapatitos de cristal por la amplia escalinata de palacio. El príncipe espera al pie mirándola arrobado, firme en el traje de gala que incluye kepí, guantes blancos y botas de charol. Sus manos se tienden hacia las mías, que he preferido llevar desnudas para que los brillantes reluzcan”. (Quesada, 2005, p. 14)
}

Como es evidente, aquí podría hablarse de una suma de realidades (una convencional y una inventada) que, en el juego paródico del narrador, se trasponen, se mezclan, para dar como resultado esta discursividad especial, fruto de la "imaginación", de la libre invención. Esto hay que ligarlo con lo que se refirió en relación con la sátira menipea. La particularidad más importante de este género, como se explicó antes, consiste en que la fantasía y la aventura se motivan, con el propósito de crear situaciones excepcionales que pongan en entredicho cualquier idea fija.

Ciertas características de la menipea y de los géneros emparentados con ella podrían extenderse, de alguna manera, a El gato de sí mismo. El objetivo de esta parte del artículo está, precisamente, en encontrar el parentesco entre estos géneros y la novela de Quesada, para, así, aclarar su carácter polifónico. Ante todo, es necesario caracterizar la imagen del narrador y el tono de la narración. El narrador es, en esta novela, el mismo protagonista. Él es el personaje de sus propias narraciones y, desde una perspectiva monológica, como se ha dicho, podría caracterizársele como un "loco" o, mejor, como una "loca". Este último término se usa generalmente para referirse de manera injuriosa a sujetos de la «comunidad gay», sobre todo a aquellos que "exponen", que "exhiben" características ligadas a lo femenino. La injuria "loca" centra toda la atención en la "desviación" sexual; sin embargo, el mismo término en masculino -"loco"-, se refiere, sobre todo, a la persona que ha perdido la razón. ${ }^{4}$ Es importante no obviar, a lo largo de este análisis, la diferencia en la relación entre el padre y el mismo protagonista de la novela de Quesada: como se verá, el padre, contrario al hijo, es un loco sin sentido, es un hombre que ha perdido totalmente el juicio. Al respecto, léase la siguiente cita de la novela:

\footnotetext{
El don Luis de trapo no sonríe, ni ronca con desenvoltura y gozo sobre el hombro de la bestia [Rasputina es quien lo carga]. [...] Luego de avanzar unos pasos, le consulta a Rasputina quién es ella. [...] Después empieza a llamar a una tal Evelia, "por favor recuérdele que esta tarde nos vemos a la sombra del sauce en el parquecito japonés", dice. (Quesada, 2005, p. 137)
}

Y, en otra parte de la novela, afirma el detective Leandro Amador: "«Tal vez doña Tina no comprende, me parece que su hermano no quiere comprender tampoco, pero don Luis hace tiempo dejó de estar bien de la cabeza. Sé que sale de esta casa, y apenas en la esquina pierde la noción de dónde está»” (Quesada, 2005, p. 187).

Así las cosas, se va, pues, a resemantizar el término "loca", que, a la luz de la teoría expuesta y para el caso de Germán Germanóvich, sólo puede entenderse positivamente. La «loca», en esta novela, es un hombre fuera de lo común, un hombre no como todos, para utilizar la expresión bajtiniana. Con este trabajo, entonces, se quiere revalorar este término, quitándole 
su carga injuriosa, para resaltar su carácter productivo. Así, el personaje "loco/loca" de esta novela, sólo lo sería, realmente, desde el discurso monológico, pero no desde la perspectiva de la literatura carnavalizada. En efecto, el tono de este narrador-personaje es ambiguo. Su discurso es internamente dialogizado y lleno de polemismo:

\begin{abstract}
«Muchas gracias, jefe», digo amablemente y el conductor no me contesta. Enciende el radio, y a pesar del súbito ruido del merengue-house puedo oír las gradas resentirse por mi peso. Entonces maldigo al chofer, al autobús, al avaro destino, pues mi entrada triunfal a Cartago tiende a volverse miserable. Ya no desciende Marylin Monroe por la escalinata del avión saludando a las tropas sino yo, con un crujido que insinúa cuán gordo debo estar o me recuerda que todo se ha hecho viejo aquí, o más bien que sigue viejo. (Quesada, 2005, p. 15)
\end{abstract}

La novela inicia, precisamente, con una polémica que obliga al narrador-protagonista a volver a su ciudad natal. De hecho, es una polémica con el padre la que mueve todo el texto desde el principio, y así queda claro con lo que el narrador refiere al respecto de su conflictiva relación padre-hijo:

\begin{abstract}
¿Mi padre? ¿Don Luis Dieciséis necesita bondad? No lo creo. Yo empecé a peregrinar porque le pedí al Rey que fuera bondadoso y él no me entendió. Por el contrario, creyó que lo insultaba, me maldijo y me obligó a marchar sin espada, corcel ni armadura. Vencí a mano desnuda a los enemigos [...]. Si alguna vez quise regresar al reino, don Luis dejó sin respuesta los despachos de los embajadores que lo alertaban de mis intenciones. Mandó a cerrar fronteras, puso en alerta los buques de guerra, apostó arqueros en las cimas de las montañas por si acaso intentaba llegar volando. (Quesada, 2005, p. 23)
\end{abstract}

Es realmente Dios quien le señala a Germán la relevancia de su regreso, sobre todo por la situación actual de su padre, su acusador: "Recuerdo a Dios para que me ponga de nuevo en situación y Él me dice al oído: «volviste a Cartago a poner término a un vejamen. No lo olvidés»" (Quesada, 2005, p. 16).

El narrador-protagonista también polemiza con los otros personajes (con Rasputina, por ejemplo) y hasta con el espacio mismo (véase, al respecto, toda la introducción a la ciudad natal, ciudad que le resulta al narrador difícil de reconocer): al comenzar la novela, el narrador polemiza indignado por un Cartago viejo desde siempre y por sus ciudadanos que pasan, escuchan y huyen. Como es claro, estos son el estilo dialogizado y ambiguo y el tono del relato típicos de la menipea.

Toda la descripción de la "noble" y "leal" ciudad de Cartago está impregnada por lo que Bajtín llama una manifiesta actitud de "familiaridad” y "profanación”. No se debe dejar de lado que la burla a Cartago es una burla no sólo a la ciudad natal sino, más importante aún, a la «casa del padre». En este sentido, la travestización paródica en torno a Cartago desmitifica, asimismo, el lugar de una de las ciudades más emblemáticas para la "identidad" costarricense: la "noble" y "leal" ciudad de Cartago no es sino, en este relato, la cuna de todos los males, una ciudad infernal, que disminuye a sus habitantes, como se verá con las afirmaciones de Germán Germanóvich.

La sátira en torno a los edificios claves en este lugar es, en este sentido, altamente significativa, sobre todo en relación con la casa del protagonista (el Palacio de Versalles). El juego de travestización del espacio, entonces, participa de la actitud satírica: no extrañan, pues, las relaciones que el narrador construye entre Cartago y París, entre su familia y la realeza. La irreverencia, en este aspecto en específico, se establece a partir de una descripción estructurada sobre oxímoros y disparidades carnavalescas. La relación de la familia del narrador-protagonista con la realeza no se puede sino entender, acá, como un rebajamiento, propio del simbolismo carnavalesco. Lo anterior se ejemplifica desde el nombre que Germán 
le da a su casa: la Familia Đ El Gado no es sino la Familia del Bacalao. 'Gado' proviene del nombre científico, en latín, del pez 'gadus morhua', el bacalao común.

Es claro, a lo largo del texto, que Germán abjura, con su parodia, del nombre del padre, de la ciudad del padre, del lenguaje del padre, etc. El narrador-protagonista, por ello, se regodea en la renominación, a partir de su creatividad y gusto. De ello se explica, además, toda su labor desestructuradora de lo «establecido». La manera en la que Germán entiende el mundo adquiere, con lo anterior, un tono totalmente irónico, que busca poner en entredicho un sistema -representado en su padre- que coarta, que condena, que exilia.

Véanse, ahora, algunos fragmentos característicos de esta novela:

\begin{abstract}
Seguro los arquitectos discuten el rescate de la estructura, los curadores dedican semanas a evaluar el estado de muebles y otras obras de arte, cada experto prepara un diagnóstico. ¿Pero quién les escucha si en Versalles no hay rey? Es cierto: Su Majestad aún duerme y come allí. Nadie le ha cortado la cabeza tampoco, pero ya no tiene los pensamientos en su lugar. Hace unos días lo asaltaron y quedó loco. Por eso Dios me envió. [cursiva agregada] (Quesada, 2005, p. 20)

Debo perdonarle su atrevimiento de creerse una igual [se refiere a Rasputina, la empleada de la familia], al fin y al cabo ha permanecido en la familia por varias generaciones. Ella ayudó a la Reina Madre a parir y le puso colorete en las mejillas a la hora de amortajarla. Se hizo cargo del príncipe Alberto y de mí, por lo que nunca nos faltó camisa blanca para la escuela ni alguien a quien odiar como progenitora. Ella ha estado junto a Su Majestad el Rey hasta en los momentos peores, conoce bien mi historia de abdicación al trono y, aunque siempre me critique y lleve chismes a la prensa, sabe que abdiqué por amor. Donde otros tiene el corazón ella no tiene nada, pero yo sé que usa ese vacío para quererme un poquito. [cursiva agregada] (Quesada, 2005, p. 22)
\end{abstract}

En las citas anteriores, se han resaltado las frases más evidentes de familiarización y profanación, los rebajamientos, etc. La novela de Quesada, en general, está cargada de estos elementos. Evidentemente, las características que se han apuntado sobre la menipea, se recogen acá de manera muy concentrada. En este sentido, es necesario repasar el problema del carnaval, para evidenciar mejor la carnavalización de este tipo de género.

Bajtín se refiere a la carnavalización ${ }^{5}$ como "[...] la influencia determinante del carnaval sobre la literatura, y sobre todo en su aspecto genérico" (Bajtín, 2003, p. 178). No se va, aquí, a revisar todo lo relativo a esa forma de "espectáculo sincrético con carácter ritual" que fue el carnaval, sino que se va a señalar la transposición del carnaval al lenguaje literario. En general, los rasgos más relevantes del carnaval son los siguientes:

a. El carnaval activa una vida carnavalesca; es decir, una "vida desviada" de su curso normal. Con esto se aniquila, según Bajtín, toda distancia entre las personas y empieza a trabajar lo que él llama "el contacto libre y familiar entre la gente" (Bajtín, 2003, p. 179).

b. Con el carnaval se elabora una nueva forma de acceder a la realidad, una forma marcada por el juego. Así, se liberan del poder de toda situación jerárquica el comportamiento, el gesto $\mathrm{y}$, sobre todo, la palabra.

c. La excentricidad es otro rasgo fundamental para la visión de mundo carnavalesca; según Bajtín, "[...] la excentricidad permite que los aspectos subliminales de la naturaleza humana se manifiesten y se expresen en una forma sensorialmente concreta" (Bajtín, 2003, p. 180).

d. Las disparidades carnavalescas, asimismo, participan de esa actitud libre y familiar del carnaval. Estas activan una serie de combinaciones que, muchas veces, conjugan los opuestos. 
e. La quinta categoría carnavalesca es la profanación, los sacrilegios carnavalescos, todo un sistema de rebajamientos, las obscenidades relacionadas con las fuerzas generadoras de la tierra y el cuerpo.

Afirma, finalmente, Bajtín:

\begin{abstract}
Estas categorías carnavalescas, y ante todo la de la libre familiarización del hombre y del mundo, durante milenios se iban trasponiendo a la literatura, sobre todo a la línea dialógica del desarrollo de la prosa novelesca. La familiarización ha contribuido a la destrucción de la distancia épica y trágica y a la trasposición de todo lo representado a la zona del contacto familiar, se ha reflejado significativamente en la organización del argumento y de sus situaciones, ha determinado una específica familiaridad de la posición del autor con respecto a los personajes (imposibles en los géneros altos), ha aportado la lógica de disparidades y de rebajamientos profanatorios y, finalmente, ha influido poderosamente en el mismo estilo verbal de la literatura. (Bajtín, 2003, p. 180)
\end{abstract}

Con lo dicho, la naturaleza carnavalesca de la menipea se manifiesta con gran obviedad, sobre todo en lo que se refiere a la libre familiarización, al escándalo y a las excentricidades, a las uniones dispares, a los rasgos naturalistas bajos, a la utopía, a la aventura y a lo fantástico.

El gato de sí mismo, a partir de lo anterior, recoge rasgos de la menipea carnavalizada. Sobre todo, recoge -como se verá- lo fantástico en la narración del protagonista, así como la excepcional libertad de la invención temática y filosófica. Igualmente, esta novela juega con muchos géneros intercalados, sin perder su tono de marcados contrastes, su tono, podría decirse, excéntrico. Al respecto de lo dicho anteriormente, véase la siguiente cita de la novela:

«Don Luis está tomando el sol», me indica la criada, la bruja, la falsa consejera, mientras hurga en los
baúles con la boca hecha agua de pura codicia. Se ha convertido en una enana y se empina tratando de
alcanzar los bordes de cedro del baúl. Sube a ellos, camina haciendo equilibrio, se deja ir gozosa sobre
los tesoros gritando "son míos, míos, todos míos". Mientras tanto la falda se le ha levantado y me muestra
su trasero enorme e indecente, apretado bajo un calzón de manta. Yo me hago el desentendido, al fin y al
cabo estoy por encima de la riqueza material y la vulgaridad de la plebe. (Quesada, 2005, p. 24)

Como es evidente, la narración es mezcla de detalle fantástico, naturalista bajo y profanador - la criada se transmuta y muestra su trasero enorme al "príncipe" que regresa a su casa paterna-, lo que produce un ambiente de rebajamientos que llevan al texto a los ámbitos de la parodia. Bajtín señala que la parodia es orgánicamente ajena a los géneros "puros" (la epopeya, la tragedia). La parodia pertenece a los géneros carnavalizados, en los que parodiar significa destronar, alterar, volver ambivalente.

La narración se desarrolla, entonces, gracias a la situación excepcional de Germán, gracias a la singular conciencia de este narrador-protagonista. Su fantasía, su "locura", le permite una completa libertad en el acto de contar mismo, en el acto de contarse. De ello se deduce la importancia de la narración de su vida como una "vida desviada", lo que, asimismo, le ayuda a liberarse de las jerarquías, a liberarse del padre, en tanto figura de poder, de control. El padre, en esta novela, es un padre destronado, totalmente rebajado, hasta el punto de parecer un muerto en vida.

El carácter multigenérico de esta novela de Quesada ya se ha señalado con los diferentes extractos que se presentaron anteriormente; sin embargo, véase también el siguiente ejemplo dentro del discurso religioso:

Con mucho trabajo pude oír la diatriba de Su Majestad. Sospeché que simplemente repetía un discurso preparado por sus asesores, el príncipe Alberto el primero de ellos: Queridos míos, hablemos de la vergüenza como fuerza motora de la vida [...] Hijitos, os lego mi receta para cocer supervivencia: enterraos en vida, negad el afecto, deciros que no hay algo ardiente en vuestro corazón, entrad al molde aunque os cause un dolor más prolongado que la eternidad. [...] Sabias son mis palabras: dejaos formar por la decencia o sucumbid en vuestra rebeldía. (Quesada, 2005, p. 62) 
La puesta en escena de diferentes géneros no es, como se ha visto, gratuita: la pluralidad de estilos y tonos en este texto dependen de esta característica en específico. Además, hay que tener presente que los géneros intercalados (como apunta Bajtín en su análisis sobre la menipea) se dan con diferente grado de parodia y objetividad. Para el caso de El gato de sí mismo, podría decirse que este carácter multigenérico es activado, precisamente, por la excepcional forma de narrar de Germán. Si Bajtín señala a la creación de un argumento excepcional como el rasgo distintivo del método de Dostoievski, aquí se debe indicar que, para Quesada, lo excepcional está no tanto en la creación del argumento sino en la forma de contar misma. Véase, al respecto, el siguiente "romance tradicional" cantado, en la novela, por un ciego en un autobús:

\author{
En el reino de Cartago \\ Un rumor se ha esparcido \\ Al pobre rey de los mundos \\ No le queda más que un hijo. \\ Cegado por la cólera \\ Sus tropas a San Francisco, \\ Coris y El Arrabal envió \\ Con trompetas y un edicto: \\ «Olvidad si alguna vez \\ Visteis levantar castillos \\ Con arena de infancia, \\ No piéis cual los yigüirros \\ Acabad con la memoria \\ Ingrato tiempo del niño». \\ Hoy Germán no se menciona \\ Su nombre está prohibido \\ Hace penar al monarca \\ Y al infractor ir a presidio. (Quesada, 2005, p. 85)
}

Y con lo dicho, el argumento de esta novela podría plantearse como excepcional, en la medida en que va contra el "orden de las cosas" (como define Bourdieu [2004] a aquello que se concibe como "natural"); es decir, en la medida en que se trata de la vida de un sujeto "desviado": se está, acá, ante la historia de rechazo, exilio, huida, reencuentro y ruptura final de Germán (un "homosexual") con su familia y su ciudad natal, como ante la historia de su amor por otro hombre. Como es evidente, este argumento es excepcional para el paradigma patriarcal, paradigma que establece las cosas que se pueden decir y las que no.

Al respecto de los géneros intercalados, véase, además, la siguiente narración en tono de cuento de hadas:

\footnotetext{
La vieja [se refiere a Rasputina] se había sentado en posición de loto, peripuesta su frente con una almendrilla hecha de pétalo de rosa. El adorno empezó a brillar y a hipnotizarme, mientras al fondo se oía a la malvada contar con su voz de tonel: Hubo una vez un reino donde todo era felicidad. Cada minuto de la rutina se engarzaba tan plácidamente con sus pares, que la realidad se había vuelto invisible y simulaba bondad, gentileza y eternidad. En un palacio arrancado a la piedra de una montaña, esculpido palmo a palmo por sensibles esclavos senegaleses y adornado con argamasa, vivían un Rey de cetro de oro y su hechicera, llamada Rasputina. Tan alto sobre el mundo estaba el magnífico edificio, que un manto de nubes lo rodeaba permanentemente. El Rey llevaba siglos recorriendo las extensas salas, cámaras, bibliotecas y jardines de palacio, dando órdenes a una legión de servidores que se inclinaban ante cada petición y desaparecían prestos en el aire. Todo estuvo bien hasta dos noches atrás, cuando se produjo una ausencia y Rasputina, la doble, tuvo miedo. (Quesada, 2005, p. 30)
}

Este "cuento de hadas" introduce uno de los elementos más relevantes de esta novela: Rasputina, en esta parte, dará a conocer cómo el Rey, don Luis, escapa de palacio una noche cualquiera. Activará, así, la desgracia que hará que Germán regrese a Cartago, desgracia que 
no es sino lo que Bajtín llama «el escándalo». Como afirma Bajtín, lo significativo de esta situación especial es que rompe "[...] «los hilos pesados» de la mentira oficial y personal y se quedan al desnudo las almas humanas, horribles como en el infierno o, por el contrario, claras y puras" (Bajtín, 2003, p. 213).

En efecto, la novela busca develar el misterio en torno al padre, misterio que también envolvió a Germán en su momento (ya se vio con el "romance tradicional" citado anteriormente) y que, con su reencuentro, se reactiva como un núcleo que une y, a la vez, separa a ambos sujetos. Ahora, tómese en cuenta el siguiente fragmento de la novela sobre la "desgracia” específica de Germán:

«Es suficiente, Germán», bramó Su Majestad cuando el silencio se asomó a mirar el espectáculo de la hoguera [lista para Germán, quien sería castigado por su "indecencia"]. La voz del rey descendió atronadora desde el cielo a la cocina. «Te hice muchas advertencias, creí que ibas a corregirte, pero seguís en boca de toda la ciudad, avergonzándonos a tu hermano y a mí». (Quesada, 2005, p. 61)

Es claro cómo ambos personajes se convierten (en distintos tiempos) en la desgracia en/de Cartago. La desgracia, como suceso adverso, no es sino, acá, la consecuencia final del escándalo. Ser la desgracia es ser el provocador mismo del escándalo.

La ciudad de Cartago, como se puede deducir con la lectura de esta novela, es una ciudad infernal. El narrador-protagonista, por lo menos, así la construye: "El poder maléfico de Cartago está en sus paredes, por eso y por la neblina la ciudad solamente se deja querer con amor malsano: lleno de golpes y cortaduras, de dolor y represión, de caricias y estrangulamientos, de odioamor." (Quesada, 2005, p. 299). Cartago es, en este texto, el infierno mismo y, en este sentido, el viaje de regreso de Germán a su ciudad natal, es un viaje al inframundo. Pero esta caracterización no se debe entender de manera totalmente negativa: este viaje (como todo viaje al infierno, desde la perspectiva carnavalesca y según las afirmaciones de Bajtín), activa un sentido más auténtico de las relaciones mutuas y de sus personajes, determinados por este contexto. Al respecto, véase la siguiente cita de Quesada:

\footnotetext{
Pocas cosas conmueven a Cartago, ciudad que no cambia desde que se inventó el recuerdo. Una de ellas es la desgracia ajena. ¡Que se haga pública la miseria privada! ¿Que se exhiba en los cines Apolo y París, mientras las ratas corren por la platea y las pulgas se abalanzan voraces sobre los espectadores! [...] Que camine a paso justo, no tan rápido como para volverse invisible, ni tan despacio como para no darle oportunidad a los parroquianos de murmurar a sus espaldas. Lo bueno, cuando se sabe, no anima el ánimo, es peligroso porque puede provocar envidia y un dolor inmerecido a quienes procuran que nada pase en la vieja ciudad. La desgracia muestra la sana implacabilidad de la vida, nos recuerda nuestra condición terrenal y, cómo negarlo, tiene su toque de humor. (Quesada, 2005, p. 29)
}

Las escenas carnavalescas adquieren un lugar muy importante en esta novela. Estas escenas podrían parecer, desde una perspectiva monogal, injustificadas; sin embargo, es clara su verosimilitud -con respecto a la realidad que se construye en el texto- y su valor artístico. Estas escenas corresponden al estilo de toda la novela, a su organicidad. El gato de sí mismo, gracias a su elemento fantástico, pone de manifiesto la lógica carnavalesca, sobre todo en lo que se refiere al misterio (otra variante de la menipea). Así, los personajes en esta novela se encuentran en lo que Bajtín llama el «umbral» (de la vida y la muerte, de la mentira y la verdad, de la razón y la demencia), y todos participan de la necesidad de develar ese misterio: la caída de las máscaras en torno a la familia Đ El Gado. Dice Germán:

Como se revelará alguna vez en los libros de historia, el contenido de la proclama se ha adelantado a su propia enunciación. ¿De qué otra forma saben los súbditos que he regresado para descubrir la verdad? Podría atribuirlo a la intuición, o tal vez sea la sabiduría popular, siempre más grande, sólida y permanente que aquella cocida lentamente por los ilustrados. [cursiva agregada] (Quesada, 2005, p. 140) 
Respecto a las escenas carnavalescas, en su relación con el elemento fantástico en esta novela, véase la siguiente cita:

\begin{abstract}
"Rasputina pensó que el gato don Luis necesitaba quedar a solas. Nunca se habían unido ni separado en su presencia. El Señor siempre tan discreto, tan bueno, él no la hubiera asustado revelándole ritos de tal magnitud. Haciendo una reverencia, la vieja salió de la habitación real sellando las puertas de cedro, corriendo los cortinajes de terciopelo y seda. Pero como quería apropiarse del secreto de la transmutación para controlar aún más a Su Majestad, se despegó la oreja izquierda y con un poquito de saliva la fijó a la puerta. [...] Por supuesto, ni aún las hechiceras más perversas son siempre eficaces. El eterno zumbido interfería seriamente en su capacidad para percibir los acontecimientos en la habitación real. La oreja izquierda, aunque libre de bichos, tampoco estaba en muy buenas condiciones. [...] Rasputina quería saber si el paso de animal a hombre resquebrajaba huesos, producía alaridos en la carne, quejas desde un pulmón que evolucionaba, pero los sonidos le llegaban sucios e inciertos, contaminados por la conversación en sueco de unos radioaficionados y por una sesión de sexo telefónico que en un principio la escandalizó, pero que rápidamente despertó su interés y una comezón sabrosa en su entrepierna reseca y en sus pezones enormes y negros como dátiles olvidados al sol. Quiso escuchar los sonidos de la metamorfosis, pero solamente pudo captar la transmisión en vivo de una pelea en Las Vegas, un especial de boleros de Marga Montoya, un mensaje en clave de los servicios de espionaje chinos y una llamada al espacio en varios idiomas intergalácticos, lanzada para ver si al fin, algún día, los extraterrestres se dignaban a contestar y a establecer contacto." (Quesada, 2005, pp. 45-46)
\end{abstract}

De acuerdo con lo apuntado anteriormente, esta novela juega con los diferentes rasgos asociados a la menipea carnavalizada. Es importante, entonces, revisar lo relativo a sus elementos utópicos. La utopía, en El gato de sí mismo, está en la añoranza de Germán por Íñigo, su amado. Íñigo se construye como un sueño que establece una situación excepcional, imposible en la vida normal. Como es claro, esto no se aleja de lo referido sobre la menipea. Según Bajtín, el sueño de sentido artístico específico se introduce como la posibilidad de una vida distinta, organizada con otras leyes muy diferentes a las de la vida habitual: "La vida que aparece en un sueño suele establecer una perspectiva con respecto a la normal, obliga a entenderla y apreciarla de una manera novedosa (a la luz de una posibilidad diferente). El hombre en el sueño llega a ser otro [...]" (Bajtín, 2003, p. 216) Íñigo, en efecto, representa, para el narrador-protagonista, otra vida posible:

Empiezo a contarme mi historia mucho antes de encontrarnos, Íñigo, pues cuando la maravilla ocurra y podamos vernos, hablar y tocarnos cual si fuésemos verdades, no querré desperdiciar nuestro poco tiempo eterno con detalles sobre qué fue de mi vida y hasta dónde me llevó la desesperación de mis pasos. (Quesada, 2005, p. 56)

El viaje fantástico es otra forma de lo utópico, dentro del género de la menipea carnavalizada. En sí mismos, el sueño y el viaje fantástico funcionan como variedades genéricas y, en general, se ligan con la utopía. En la novela El gato de sí mismo, el viaje fantástico se puede encontrar en la descripción que se hace del movimiento del personaje de Cartago hacia Santa Cruz. El narrador huye hacia tierras más benévolas con el fin de evitar la tiranía paterna. Este viaje a Santa Cruz, en realidad, se da tanto porque el narrador es expulsado de Cartago por "indecente", como por su necesidad por huir de allí. Santa Cruz es otro mundo, marcado por el elemento utópico. Los mismos habitantes son descritos con cualidades "excepcionales". $\mathrm{Al}$ respecto de lo anterior, véase la siguiente cita:

Así llegué a Santa Cruz, un pueblo situado al otro extremo de los cuentos de hadas, donde yo tendría calor perenne y el anonimato indispensable para sentarme a escribir mis memorias en doce tomos y un epílogo, libro inspiracional y guía práctica para una vida mejor, además de gran herencia. [...] Santa Cruz me gustaba por cosmopolita. Había dos restaurantes chinos, es decir una influencia cultural enorme de las gloriosas dinastías Xia, Qin, Ming y Tung. Los árabes se habían instalado hacia el norte, cerca de donde estaba enterrado el último camello que cruzó esas tierras. Había industriosos nicaragüenses, salvadoreños expertos en pupusas, una tortillera famosa porque palmeaba las tortillas al modo tradicional [...]. También, he de confesarlo, tenía un amor de circunstancia. [cursiva agregada] (Quesada, 2005, p. 91) 
Santa Cruz, en oposición a Cartago, crea una situación de extrañamiento a partir de las múltiples posibilidades que este "nuevo mundo" representa para Germán. La oposición que se hace en el texto no puede ser mayor, y las características paradisíacas que adquiere el lugar apuntan a su excepcionalidad. La relación de Germán con Yaneri Solitari es, en este sentido, el ejemplo más claro de ese carácter «delicioso» que adquiere Santa Cruz en el texto:

\footnotetext{
Esa noche, Yaneri Solitari y yo nos amamos saludando a la bandera, cantando a las bellezas, al orgullo del país y a la urgencia de amar a la nación. Dibujamos primeras letras en nuestras espaldas y muslos. Imprimimos mapas de sudor en el verde oscuro de los pizarrones. Sumamos, dividimos y multiplicamos placer bajo nubes de tiza. Yaneri Solitari y yo fuimos tan felices, Íñigo, que por unas horas te puse en esos páramos donde el recuerdo no escuece. (Quesada, 2005, p. 93)
}

Los constantes movimientos temporales en El gato de sí mismo, el mismo "recordar" que muchas veces activa la narración del protagonista, son típicos del estilo y composición de los textos ligados a la menipea fantástica. Esta novela, en efecto, se sostiene por una singular estructura, caracterizada por el desuso del tiempo histórico y biográfico permanente. Según Bajtín, este tipo de textos, más bien, "pasan por encima" del tiempo épico y provocan que se pierdan todos los límites temporales. Como es claro, esta concepción artística del tiempo y del espacio sobrepasa la verosimilitud empírica elemental y la lógica superficialmente racionalista, según lo señalado por Bajtín para el caso de Dostoievski.

Finalmente, se puede afirmar que el método de presentación artística de El gato de sí mismo evidencia su ligamen con la novela polifónica, como se ha podido colegir a partir del análisis trabajado. Los rasgos que ya se han señalado, asimismo, muestran su vinculación con la menipea carnavalizada.

\section{A manera de conclusión}

Como se ha visto, la novela de Quesada participa de los rasgos más característicos de lo que Bajtín ha llamado la novela polifónica. Uno de estos rasgos es la imagen ambivalente de algunos personajes en este tipo de textos. Para el caso de la novela costarricense, esto se evidencia -como se trató de demostrar- en el narrador-protagonista. La «excentricidad» de Germán es parte fundamental de su humanidad; es decir, su humanidad no se puede concebir sin los elementos de cierta "locura". Sin embargo, como ya se ha dicho, esta locura no es para nada negativa, es más bien deseable en este tipo de personajes ambivalentes, personajes que, sin embargo, son conscientes de su excentricidad. La plenitud de autoconciencia (como apunta Bajtín para el caso de Sueño de un hombre ridículo, de Dostoievski) es, entonces, representativa en Germán Germanóvich, como, en general, lo es en este tipo de personajes que conocen mejor que nadie su "locura"; al respecto, la siguiente cita:

\footnotetext{
Pensándolo bien, en todo reencuentro que se precie hay un abrazo de por medio, quizás me falta ese ingrediente mágico. Entonces pongo mi maleta junto a la base del falolápiz y me dedico a pedir abrazos. Algunos transeúntes apuran el paso y me ignoran con un gesto [...]. En definitiva pasan las personas, me escuchan y huyen. [...] No falta quién ría, se asuste o haga un comentario insultante, pues es cosa de locos y vagabundos eso de pedir abrazos. [cursiva agregada] (Quesada, 2005, p. 17)
}

Germán, entonces, pertenece a este grupo de personajes a los que Bajtín caracteriza como estrambóticos, pero que -al mismo tiempo- tienen una aguda conciencia de sí mismos y de todo. Son personajes que, además, no poseen ni un poco de ingenuidad. Evidentemente, este hombre que sabe la verdad, que la busca y del cual se ríen todos, es una parte importante de la estructura de esta novela. Según Bajtín, la posición que adquiere este tipo de personajes 
en la novela polifónica es característica del sabio en la menipea, el sabio como portador de la verdad, pero una verdad que los demás consideran locura o estupidez.

Otro aspecto que ha de llamar la atención es que, en El gato de sí mismo, casi no hay diálogos estructuralmente expresos; sin embargo, todo el discurrir narrativo de Germán, el narrador-protagonista, está marcado por un diálogo interno. Es necesario, sobre este punto, citar a Bajtín: "[...] aquí, todas las palabras van dirigidas a uno mismo, al universo, a su creador, a todos los hombres. Aquí, como en el género del misterio, la palabra se expresa frente al cielo y la tierra, es decir, frente al mundo entero" (Bajtín, 2003, p. 226). El diálogo interno presente en esta novela se puede ejemplificar con la narración del encuentro entre Germán y Leandro Amador (quien investiga el "asunto" que envuelve al padre de Germán):

\begin{abstract}
Apenas unas horas antes mis rasgos físicos eran diferentes. Recuerdo haberme levantado con el aura de Thomas E. Lawrence. Me encantaron mis ojos azules, mi apuesta presencia en el traje blanquísimo de libertador. Algunas veces, sin embargo, tiendo a mutar sin darme cuenta y al anochecer he caído en el catre como Edward G. Robinson cuando muere acribillado por la policía. [...] Quizás Leandro se confunde, porque sus conocimientos de historia y de cine no han de ser tan profundos como los míos. Para ponerlo a prueba, pongo cara de Greta Garbo moribunda, pero no reacciona. [...] Leandro Amador tiende a confundirme. Se refiere constantemente al príncipe Alberto con una familiaridad que ni yo mismo me permito. [...] No quiero confesarle hace cuántos años no veo a Alberto [...]. (Quesada, 2005, pp. 171-172)
\end{abstract}

Los dobles que aparecen en la novela también son relevantes en relación con el héroe de El gato de sí mismo y, por lo tanto, con su estructura. En esta novela, Germán explicita su pluralidad a partir de sus otros yoes, que, como el primero, juegan con la realidad, juegan con su propia existencia. Los dobles hay que ligarlos al carácter fantástico que adquiere el texto, ${ }^{6}$ en relación con los giros propios de la menipea carnavalizada:

\footnotetext{
Leandro me mira insolentemente, como haciendo un reclamo. "Yo no existo", quisiera decirle, "puedo desaparecer en cualquier momento". Sin embargo, mi presencia en esa sala desmentiría cualquier manifestación en tal sentido. Para peores, ya no somos dos Germán Germanóvich sino tres, pues acabo de desdoblarme en uno de traje con pajarita, cuyo suave dejo polaco me advierte que ahora soy Józek Teodor Korzeniowski. Me siento en un sillón libre, saco de mi bolsillo pluma y papel y a dúo con Leandro Amador vuelvo a buscar el corazón de esta cebolla que es el asunto [...]. (Quesada, 2005, p. 175)
}

Finalmente, es necesario resaltar un tema que Bajtín liga a la menipea cínica o estoica y que aparece en el cierre de la novela costarricense: la indiferencia absoluta respecto a todo lo que hay en el mundo. En efecto, en el "Epílogo y rebobinado", el tono de Germán cambia, y cambia tanto que el cierre del protagonista es más bien una despedida del mundo, un suicidio:

\footnotetext{
Y ahora que voy rumbo al último escondite en esta tierra, que el medio día está sobre mí y la gloriosa caravana del príncipe Alberto se cruza con mi autobús, ahora que los pienso a todos y sé que no los volveré a ver sino hasta cuando crucemos con Caronte hacia la orilla de Hades, me queda el consuelo de haber sido coherente con mi vida. (Quesada, 2005, p. 343)
}

Como es claro, El gato de sí mismo está todo compenetrado de elementos de menipea, así como de los géneros relacionados (piénsese, al respecto, en la diatriba, el soliloquio, la confesión, etc.). Como explica Bajtín, muchos cambios se han dado en todos estos géneros, los que, sin embargo, han conservado su naturaleza. Esta, finalmente, es la que determina la estructura del argumento y la composición de toda la novela polifónica y de ello se deduce su importancia.

Así las cosas, se recocieron, en El gato de sí mismo, las manifestaciones de la naturaleza genérica de la menipea, como núcleo central de la novela polifónica. Al mismo tiempo, se demostró cómo estos rasgos se combinan, en la novela de Quesada, orgánicamente en relación con toda la propuesta estético-filosófica de este texto. El gato de sí mismo, 
entonces, participa de las características que Bajtín señaló para este tipo de novelas. Ante todo, hay que resaltar su estructura en múltiples planos, su carencia de unidad monológica: El gato de sí mismo admite lo heterogéneo como un elemento fundamental tanto en la estructuración del texto como en la misma intención artística.

La polifonía, entonces, mueve: la estructura de una novela polifónica no es sino un ir y venir de voces, de tiempos, de espacios, de discursos, ${ }^{7}$ de, finalmente, centros que no se pueden reducir a un común denominador ideológico. En este sentido, El gato de sí mismo es profundamente pluralista, sobre todo en su tendencia a verlo todo como algo coexistente. De ello se deduce, además, que el narrador-protagonista viva todos sus tiempos en el presente más inmediato. Su mundo representa una unión de varios elementos artísticamente organizados, y es, precisamente, en este punto en donde se halla su «complejidad espiritual». Así, únicamente resta decir que el mundo de Germán sólo puede entenderse si es ubicado en la estructura misma de su «autobiografía».

\section{Notas}

1. Por supuesto, hay que tener presente que todos estos elementos no se van a repetir de idéntica forma en las novelas contemporáneas que se entiendan como polifónicas. Sin embargo, igualmente, es clara la importancia de ellos para la estructura, argumento y composición de la novela moderna.

2. Como se verá, la menipea funciona a partir de la combinación de elementos que podrían parecer incompatibles. La heterogeneidad es la característica que más resalta a la hora de estudiar este género. En este sentido, no se debe olvidar el papel fundamental de lo carnavalesco como "[...] el principio unificador que relacionaba los más variados elementos en un todo orgánico del género, principio de una fuerza y vitalidad excepcionales [...]" (Bajtín, 2003, p. 196) Y sigue este teórico: "En el desarrollo posterior de la literatura europea la carnavalización ayudó constantemente a eliminar toda clase de barreras entre los géneros, entre los sistemas cerrados de pensamiento, entre diversos estilos, etc.; eliminó toda cerrazón y toda subestimación mutua, acercó lo lejano, unió lo desunido. En esto consiste la gran función de la carnavalización literaria” (Bajtín, 2003, p. 196).

3. Desde la perspectiva planteada, se prefiere la noción de "collage" a la de "pastiche", propuesta por Uriel Quesada. Lo anterior es comprensible, en la medida en que se cancela el sentido peyorativo de este último término. El término "collage", por su parte, evidencia el carácter artístico en la labor de Germán, quien, como se verá inmediatamente, utiliza textos de diversa procedencia para construir su obra. Así, la intertextualidad habrá que entenderla no sólo como el cruce y la resignificación de diferentes textos sino, también, como una estrategia que busca - con la parodia que activa-contribuir con el ocultamiento y huida del narrador-protagonista, como se verá.

4. Y con lo anterior, como ha apuntado Foucault, es clara la íntima relación que establece el sistema psiquiátrico tradicional entre las sexualidades "desviadas" y los problemas mentales: ambos son, desde su perspectiva, diferentes formas de un mismo "monstruo". Evidentemente, lo anterior es una estrategia más de homogenización de los sujetos "inciertos", quienes son -siempre- relegados a un solo ámbito, al ámbito de lo "aprisionable".

5. Según lo afirmado anteriormente, es fundamental entender la carnavalización como un eje vertebrante de la novela de Quesada. Este autor, en efecto, siempre incorpora los diversos géneros con los que juega desde la óptica carnavalesca. Esta es la clave de la escritura de El gato de sí mismo, como se podrá colegir a partir de las siguientes afirmaciones.

6. El tema del doble ha sido muy trabajado en la literatura fantástica, aunque más en relación con la idea de lo ominoso. Así, si bien no se está leyendo esta novela costarricense dentro de este género, es importante hacer referencia al valor que adquieren los dobles (dentro de la literatura fantástica, en general) en su vínculo con la cuestión de la "identidad". Como explica Morillas-Ventura, en su artículo "Identidad y literatura fantástica": "El narrador [de los textos fantásticos] afirma su mirada oblicua, lateral, para poner de relieve la porosidad de los hechos, su acaecer y su sentido. La identidad es puesta 
en duda, investigada, debe soportar la sospecha creada por sus narradores sagaces e implacables, quienes atienden a la fluidez y al deslizamiento del significado antes que al enunciado mismo, rechazando la aparente solidez de la representación ficcional." (Morillas-Ventura, 1999, p. 317).

7. Explica Pozuelo-Yvancos que la aportación fundamental de Bajtín a la cuestión de la «otredad» es "[...] haber marcado que la comunicación entre hablantes lo es entre sujetos sociales, conciencias interactuantes en un acontecimiento, no sujetos especulares en que un yo derive del otro, sino voces o conciencias que interactúan en la comprensión o búsqueda responsable del conocimiento." (PozueloYvancos, 2006, p. 50). Y sigue: "De ahí proviene el constante interés de Bajtín, cuando analiza los géneros, la novela, las relaciones entre discursos diferentes y series como el carnaval, la parodia, etc., por situar los textos culturales dentro del marco ideológico-social, entendiendo el dialogismo de los discursos y lenguas múltiples que se interrelacionan no sólo, como se ha querido ver desde el posestructuralismo, como relaciones intertextuales, entre textos, sino como diálogo interactuante de discursos entendidos como prácticas sociales que coexisten y que ponen de manifiesto relaciones de poder o de conocimiento. Cualquier género literario es una parte integrante de un fenómeno comunicativo, social." (PozueloYvancos, 2006, p. 50).

\section{Bibliografía}

Acevedo, R. (1994). Orígenes de la nueva novela centroamericana (1968-1980). La Torre. 8 (29), 115-148.

Amoretti, M. (1992). Diccionario de términos asociados en teoría literaria. San José: Editorial de la Universidad de Costa Rica.

Bajtín, M. (1989). Teoría y estética de la novela. Madrid: Taurus.

Bajtín, M. (2002). Estética de la creación verbal. Argentina: Siglo XXI.

Bajtín, M. (2003). Problemas de la poética de Dostoievski. México: Fondo de Cultura Económica.

Bourdieu, P. (2000). La dominación masculina. Barcelona: Anagrama.

Bourdieu, P. (2004). Las reglas del arte. Argentina: Siglo XXI.

Caamaño, V. (2005). Voces marginales en "Bienvenido a tu nueva vida" de Uriel Quesada. Revista de Filología y Lingüística. 31 [extraordinario], 35-42.

Calsamiglia, H. y Tusón, A. (1999). Las cosas del decir: manual de análisis del discurso. Barcelona: Ariel.

Campbell, J. (1998). El héroe de las mil caras: Psicoanálisis del mito. México: Fondo de Cultura Económico.

Chacón, H. (2009). Monstruosidades, maravillas e intersticios en Viajero que huye (2008) de Uriel Quesada. Istmo (Revista virtual de estudios literarios y culturales centroamericanos). (19). http://istmo.denison.edu/ [Consulta: 22 de octubre de 2013].

Chacón, A. (2005). Lejos, tan lejos dentro de la narrativa de Uriel Quesada. Presentación al libro Lejos, tan lejos, de Uriel Quesada. San José, Instituto Cultural de México.

Chacón, A. (2009). Horizontes y límites de una historia de las literaturas (A propósito de la publicación de Intersecciones y transgresiones: Propuestas para una historiografía literaria en Centroamérica). Istmo (Revista virtual de estudios literarios y culturales centroamericanos). (19). http://istmo.denison.edu/ [Consulta: 3 de junio de 2013]. 
Conrad, J. (1908). Il Conde. [Versión digital]. www.feedbooks.com/ [Consulta: 01 de setiembre de 2011].

Cortez, B., Ortiz-Wallner, A. y Ríos-Quesada, V. (Eds). (2012). (Per)Versiones de la modernidad. Literaturas, identidades y desplazamientos. Guatemala: F\&G.

Coto-Rivel, S. (2007). Espacios de la marginalidad y nuevas propuestas de género: la construcción del discurso homoerótico en la novela Paisaje con tumbas pintadas en rosa de José Ricardo Chaves. (Tesis de Maestría). Universidad de Costa Rica.

Díaz, D. (2006, 2 de febrero). Uriel Quesada: 'Mi novela es un pastiche'. La Nación, Vivir. [versión digital]. http:/www.nacion.com/vivir/ [Consulta: 9 de setiembre de 2012].

Dobles, A. (1999, 26 de mayo). Cartas a La Nación: Un cuento en Áncora. La Nación. http:// wvw.nacion.com/ln_ee/1999/mayo/26/opinion8.html/ [Consulta: 28 de octubre de 2013].

Diccionario de la Real Academia de la Lengua. (2001). (22 a ed.). [Versión digital]. http://www. rae.es/ [Consulta: 22 de noviembre de 2013].

Dostoiesvki, F. (2006). Memorias del subsuelo. México: Jorge a Mestas Ediciones.

Eribon, D. (2001). Reflexiones sobre la cuestión gay. Barcelona: Anagrama.

Eribon, D. (2004). Una moral de lo minoritario: Variaciones sobre un tema de Jean Genet. Barcelona: Anagrama.

Eribon, D. (2011). Borders, Politics and Temporality. Coloquio 'Sexual Nationalisms', Universidad de Ámsterdam. http://didiereribon.blogspot.com/ [Consulta: 10 de octubre de 2013].

Fornet-Betancourt, R. (2004). Filosofar para nuestro tiempo en clave intercultural. Aachen: Concordia, Reihe Monographien/Band 37.

Foster, D.W. (2000). Producción cultural e identidades homoeróticas. San José: EUCR.

Gamboa-Barboza, I. (2009). El sexo como lo cura. San José: EUCR.

Grabe, N., Lang, S. y Meyer-Minnemann, K. (Eds.). (2006). La narración paradójica: "Normas narrativas" y el principio de la "transgresión”. Madrid: Iberoamericana/Vervuert.

Hernández, G. (2010). Reflexiones sobre la construcción del sujeto en la era post cartesiana. A Parte Rei. (26). http://serbal.pntic.mec.es/ [Consulta: 24 de abril de 2011].

Kristeva, J. (1974). El texto de la novela. Barcelona: Lumen.

Kulawik, K. (2009). Travestismo lingüístico: El enmascaramiento de la identidad sexual en la narrativa latinoamericana neobarroca. Madrid: Iberoamericana/Vervuert.

Mackenbach, W. (Ed.). (2008). Intersecciones y transgresiones: propuestas para una historiografía literaria en Centroamérica. Guatemala: F\&G.

Marquet, A. (2011). Las posibilidades de la errancia en Viajero que huye de Uriel Quesada. Excéntrica. http://www.excentricaonline.com/ [Consulta: 07 de setiembre de 2011].

Morillas-Ventura, E. (1999). Identidad y literatura fantástica. Anales de Literatura Hispanoamericana. 28, 311-321. 
Nietzsche, F. (2000). El gay saber o La gaya ciencia. Madrid: Espasa Calpe.

Obando, A. (2008). La gruta y el arcoíris: Antología de narrativa gay/lésbica costarricense. San José: Editorial Costa Rica.

Pozuelo-Yvancos, J.M. (2006). De la autobiografía. Barcelona: Crítica.

Puig, M. (1988). El beso de la mujer araña. Argentina: Fondo de Cultura Económica.

Quesada, U. (1985). Ese día de los temblores. San José: Editorial Costa Rica.

Quesada, U. (1990). El atardecer de los niños. San José: Editorial Costa Rica.

Quesada, U. (1996). Larga vida al deseo. San José: EUNED.

Quesada, U. (1999). Si trina la canaria. Cartago: Editorial Cultural Cartaginesa.

Quesada, U. (2004a). El escritor y la experiencia del clóset. Encuentro: Escribiendo desde el centro de América. Casa de América.

Quesada, U. (2004b). Lejos, tan lejos. San José: Editorial Costa Rica.

Quesada, U. (2005). El gato de sí mismo. San José: Editorial Costa Rica.

Quesada, U. (2008). Viajero que huye. San José: Editorial Uruk.

Ríos, V. (2006). «El elefante birmano» de Uriel Quesada: Una trasgresión al imaginario nacional. Káñina. 30 (2), 139-144.

Rivero, I. (2008). Intertextualidad, polifonía y localización en investigación cualitativa. Athenea Digital. (3). http://antalya.uab.es/athenea/ [Consulta: 22 de setiembre de 2012].

Sarduy, S. (1998). El barroco y el neobarroco. En Obra completa. San José: Fondo de Cultura Económico.

Zavala, M. (1990). La nueva novela centroamericana. Estudio de las tendencias más relevantes del género a la luz de diez novelas del período 1970-1985. (Tesis doctoral). Universidad Católica de Lovaina. 